\title{
Comparing motion capture cameras versus human observer monitoring of mammal movement through fence gaps: a case study from Kenya
}

\author{
Marc Dupuis Desormeaux ${ }^{1}$, Zeke Davidson ${ }^{2}$, Mary Mwololo ${ }^{3}$, Edwin Kisio ${ }^{3}$ and \\ Suzanne E. MacDonald ${ }^{1 *}$ \\ ${ }^{1}$ York University, Toronto, Ontario, Canada, ${ }^{2}$ Marwell Wildlife, Winchester, U.K. and ${ }^{3}$ Lewa Wildlife Conservancy, Isiolo, Kenya
}

\begin{abstract}
Monitoring the movement and distribution of wildlife is a critical tool of an adaptive management framework for wildlife conservation. We installed motion triggered cam eras to capture the movement of mammals through two purpose built migration gaps in an otherwise fenced conservancy in northern Kenya. We compared the results to data gathered over the same time period (1 Jan 201131 Dec 2012) by the human observers monitoring mammal tracks left at the same fence gaps in a sandy loam detection strip. The camera traps detected more crossing events, more species and more individuals of each species per crossing event than did the human track observers. We tested for volume detection differences between methods for the five most common species crossing each gap and found that all detection rates were heavily weighted towards the camera trap method. We review some of the discrepancies between the methods and conclude that although the camera traps record more data, the management of that data can be time consuming and ill suited to some time sensitive decision making. We also discuss the importance of daily track monitoring for adaptive management conservation and community security.
\end{abstract}

Key words: camera traps, tracking, wildlife monitoring

\section{Résumé}

Le suivi des déplacements et de la distribution de la faune est un outil critique pour tout cadre de gestion adaptative de la conservation de la faune. Nous avons installé des caméras à détection de mouvements pour capter les déplacements de mammifêres à travers deux passages de

*Correspondence: E mail: suzmac@yorku.ca migration spécialement créés dans une zone de conserva tion par ailleurs clôturée du nord du Kenya. Nous avons comparé les résultats aux données récoltées pendant la même période $\left(1^{\mathrm{er}}\right.$ jan 201131 déc 2012) par des observateurs qui suivaient les traces laissées à ces mêmes passages dans une bande de détection sablo limoneuse. Les camera-traps détectaient plus de passages, plus d'espèces et plus d'individus de chaque espèce que les observateurs. Nous avons testé les différences en volume entre les méthodes de détections pour les cinq espèces les plus fréquentes qui franchissaient chaque passage et nous avons découvert que les taux de détection pesaient fortement en faveur de la méthode des camera traps. Nous avons examiné certaines des différences entre les méthodes et nous en concluons que, même si les pièges photogra phiques enregistrent plus de données, la gestion de ces données peut prendre du temps et être moins adaptée pour certaines prises de décision où le temps est important. Nous discutons aussi de l'importance du suivi quotidien pour une gestion adaptative de la conservation et pour la sécurité communautaire.

\section{Introduction}

The importance of reliable wildlife monitoring is critical to wildlife conservation management (Gibbs, Snell \& Causton, 1999; Lyons et al., 2008). At semi porous conservancies, monitoring the points of ingress and egress into the surrounding communities is vitally important to reduce human wildlife conflicts with elephant (Loxodonta africana) and lion (Panthera leo). Using community based track observers can produce reliable results (Liebenberg, 1990; 
Stander et al., 1997; Elbroch et al., 2011) and can be a valuable monitoring tool (Stander, 1998; Gusset \& Bur gener, 2005; Balme, Hunter \& Slotow, 2009) although it is not without drawbacks (Burton, 2012). Camera traps have proven to be useful to detect the presence of rare or cryptic species and to monitor crossing structures (Cle venger, 2005; Balme, Hunter \& Slotow, 2009; Rovero \& Marshall, 2009; Ahumada et al., 2011; Gagnon et al., 2011), and to be a cost effective and reliable alternative to track based monitoring at crossing structures (Wolf, Elvinger \& Pilcicki, 2003; Ford, Clevenger \& Bennett, 2009; Guzvica et al., 2014).

At our study site, managers use daily reports by track observers to monitor the movement of mammals in or out of the conservancy through purpose built fence gaps as part of a multitude of other monitoring tools within their adaptive management model. Managers use the movement data collected at the fence gaps to monitor migratory patterns and predator movement into the conservancy and out to the neighbouring communities. At our study site, observers from the local communities are employed to identify mammal species by the tracks left behind and count the number of individuals that have passed through the fence gaps. The track observers report their findings on a daily basis. Camera traps were first installed at our study site in 2010 to document and monitor the movement of endangered Grevy's zebra (Equus grevyi) as part of a national effort.

The objective of this study was to examine the effectiveness, reliability and advantages of both methods in the specific context of a semi porous conservancy. We had no preconceived bias towards one method or the other and, based on previous findings, generally expected to see a close correlation between the observer and camera data.

\section{Material and methods}

\section{Study area}

Our study was conducted at the Lewa Wildlife Conser vancy (Lewa) in Isiolo, Kenya. The habitat at Lewa consists of northern acacia commiphora bushlands and thickets (White, 1983) with an afromontane section and areas of savannah. The conservancy supports over 70 species of mammals. A $142 \mathrm{~km}$ long, two metre high fence, consisting of twelve strands of alternating electrified and grounded wires surrounds the 25,000 ha conser vancy. The fence is continuous except for a few manned gates permitting vehicle traffic and three migratory fence gaps (see Fig. 1). The Northern gap leads to community pastoral lands and towards traditional elephant migratory routes. The Western gap leads to an adjoining wildlife conservancy (Borana) that also has fence gaps connecting it to the outside landscape matrix. Finally, the Southern gap leads into an elephant corridor that leads towards Mount Kenya. Camera trap and observer comparative data were available at two of these fence gaps, the Northern and Western gaps.

\section{Data collection}

We collected data between 1 Jan 2011 and 31 Dec 2012. We only compared the data from the days where we had both human observer and camera trap data. We had 560 days of comparable data from the observers and the cameras at the Northern fence gap and 474 days at the Western fence gap.

The track observers were selected from a large pool of local applicants through a competitive process that tested each candidate's proficiency at track interpretation. The successful candidates had a thorough knowledge of track identification. Each track observer monitored one fence gap, by reading the tracks left in a strip of sandy loam soil on the Lewa (conservancy) side of each fence gap. These observers monitored their respective fence gap sand traps in the mornings (approx. 8 9am). The track traps consisted of a three metre wide strip of sandy loam soil that spanned the length of the fence gaps and were kept free of vegetation, debris and other obstructions by daily sweeping, immediately after reading the tracks, thus refreshing the detection surface every $24 \mathrm{~h}$. The observers transmitted the information via VHF radio to the central operations manager on duty.

We installed three infrared motion triggered cameras (Reconyx RC60HO Hyperfire, Holmen, WI, USA) at the same fence gaps monitored by the trackers. Two cameras (Camera 1 and Camera 2) were installed at the wider $(30 \mathrm{~m})$ Northern gap, facing one another across the gap, to cover the whole span. Camera 2 data were used to confirm the species, count or direction of ambiguous crossing events captured by Camera 1. We installed one camera at the narrower $(20 \mathrm{~m})$ Western gap, also oriented across the gap. All cameras field of view were perpendic ular to the directions of wildlife travel. We mounted cameras in 'elephant proof' custom built steel housings that set the height of the camera at roughly $1.5 \mathrm{~m}$ above 


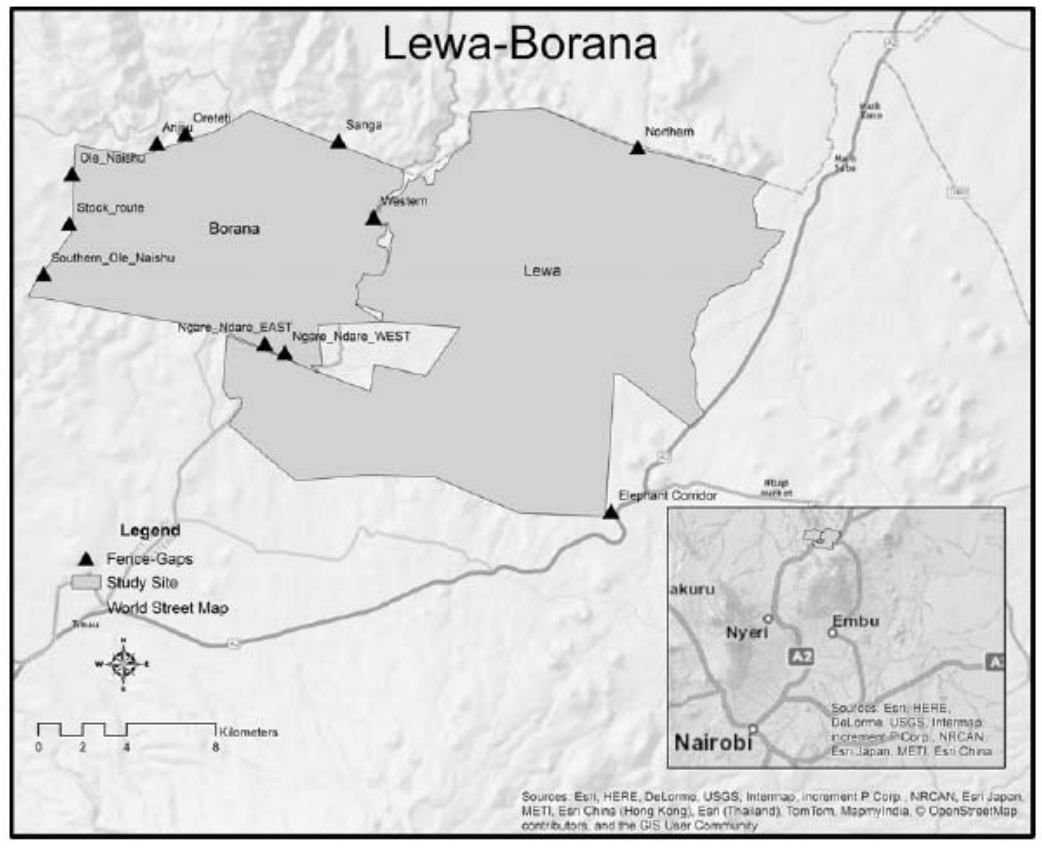

Fig 1 Map of the study site with fence gaps. (Note: data from the Northern and Western fence gaps were used in the comparative analysis.)

the ground. Cameras were configured for a three exposure burst upon being triggered by their inbuilt motion detec tors and set for rapid fire to ensure continuous shooting for as long as their sensors detected motion. Images were stored on Secure Digital (SD) memory cards. Staff collected data roughly every two weeks from the cameras. Trained observers, one of the authors (MDD) or a research assistant, catalogued the images. Interobserver reliability of the two photo data observers was calculated from a sample that was catalogued by both observers and is reported with the results.

\section{Testing agreement between the detection methods}

We compared both methods first by testing interobserver agreement between methods at the most general level by comparing the daily species detection. We defined a 'species crossing event' as the record, either by pho tographs or by tracks, of the passage of one or more individuals of a species going in the same direction (inbound or outbound) through a particular fence gap. For every crossing event, both methods recorded: date, species detected, direction of travel and number of individuals of that species crossing in the same direction (count). In the first analysis, we looked at the occurrences where one method recorded the passage of a species and compared whether the other method managed to record the passage of the same species. For this general compar ison, we did not account for the number of individuals crossing or the direction of travel, we looked to see whether the methods would agree as to which species were moving through the fence gaps. We tested the data at various levels of granularity. We first examined whether the two methods were in agreement with regard to species detection, using the pooled data from both gaps, then tested each gap separately. We tested whether the two detection methods agreed with regard to direction as well at different traffic volumes. Finally, we tested for agree ment between the detection methods for the most common individual species at both fence gaps.

\section{Testing for volume detection differences}

We tested for differences in the number of individuals detected between the methods using a paired difference test. We tested the ratio of reported counts as:

(no. of individuals detected by tracker at event $i$ no. of individuals detected by camera at event $i$ )

(no. of individuals detected by tracker at event $i+$ no. of individual detected by camera at event $i$ ) 
A ratio near zero indicated no difference between the methods. A positive ratio indicated that the trackers detected more individuals per crossing for that particular species and a negative ratio indicated that the camera traps detected more individuals per crossing event. We tested the data sets for normality of distribution of total detected individuals by performing a Shapiro Wilk test and found that neither the camera nor the tracker data sets were normally distributed (camera traps $W_{2457} \quad 0.525$, $P<0.001$; tracker $\left.W_{2457} 0.370, P<0.001\right)$. Because of the non normal distribution of the data sets, we calculated the paired difference test using a nonparametric Wilcoxon signed ranks tests.

We tested pooled data as well as data from each gap separately. We tested for the effect of volume, using the mean number of individuals per crossing events as the cut off between low and high volume days. We tested down to very low traffic volumes (less than three individuals per day) to see whether we could find a level where the methods might report more similar activity. We tested for the effect of direction on detection. We tested each common species to each gap separately in order to examine whether any of the species were equally detected. Lastly, we also aggregated the data and tested both the agreement and the paired differences with regard to the detection of lion and leopard (Panthera pardus) as these species are of specific concern to the management of human wildlife conflicts. All statistics were calculated using SPSS statistical software (IBM SPSS Statistics version 22; Armonk, NY, USA).

\section{Results}

We tested the paired data using Cohen's kappa coefficient ('kappa') to test individual interobserver reliability between the methods. A kappa of 0 is approximately equivalent to a reliability of $50 \%$, a negative kappa is less reliable, and a positive kappa indicates higher interobserver reliability. Kappa scores are divided into broad categories of agree ment, with kappa scores below zero representing poor agreement, scores of $0.00 \quad 0.20$ as slight agreement, 0.21 0.40 as fair, 0.410 .60 as moderate, 0.610 .80 as substantial and 0.811 .00 as almost perfect strength of agreement (Landis \& Koch, 1977).

Interobserver reliability between the camera trap photo observers was classified as very high with agreement on species identification (n 118, kappa 0.899, almost perfect), individual counts (n 118, kappa 0.725, sub stantial) and on direction (n 118, kappa 0.879, almost perfect). We also tested a sample of the camera data from the Northern fence gap's Camera 1 and Camera 2. We found that both cameras were in fair agreement with regard to species detection (n 64, kappa 0.333, or fair agreement) as well as detection of volume count and direction of travel (Wilcoxon's signed ranked test, In: Z 1.735, $P<0.083$; Out: Z $\quad 0.121, P<0.904)$.)

Agreement results between the detection methods are presented at the more general level in Table 1, and then by individual species in Table 2. We tested the detection of crossing events with respect to the identification of daily species detected, irrespective of the number of individuals

Table 1 Estimation of Interobserver reliability between detection methods based on daily species detection and detection difference based on total number of individuals detected per crossing for aggregated gap data (01 Jan 2011 to 31 Dec 2012)

\begin{tabular}{|c|c|c|c|c|c|c|c|c|}
\hline \multirow[b]{3}{*}{ All Species } & \multirow[b]{3}{*}{$\mathrm{n}$} & \multirow{2}{*}{\multicolumn{2}{|c|}{ Interobserver Reliability }} & \multicolumn{5}{|c|}{ Paired difference test } \\
\hline & & & & \multicolumn{3}{|l|}{ Ranks (n) } & \multicolumn{2}{|l|}{ Wilcoxon } \\
\hline & & Kappa & Strength of agreement & Negative & Positive & Ties & $\mathrm{Z}$ & $P$ level \\
\hline Both gaps & 2426 & 0.263 & Poor & 1685 & 560 & 181 & 19.929 & $P<0.001$ \\
\hline Northern fence gap & 1865 & 0.225 & Poor & 1311 & 440 & 114 & 19.417 & $P<0.001$ \\
\hline Western fence gap & 561 & 0.407 & Poor & 374 & 120 & 67 & 10.854 & $P<0.001$ \\
\hline Inbound & 1788 & 0.224 & Poor & 1235 & 435 & 108 & 19.582 & $P<0.001$ \\
\hline Outbound & 1823 & 0.208 & Poor & 1326 & 410 & 87 & 15.309 & $P<0.001$ \\
\hline Below Mean Volume $(n<6)$ & 2169 & 0.304 & Poor & 1511 & 495 & 163 & 20.804 & $P<0.001$ \\
\hline Above Mean Volume $(\mathrm{n} \geq 6)$ & 859 & 0.130 & Poor & 640 & 201 & 18 & 15.721 & $P<0.001$ \\
\hline Lion/leopard & 54 & 0.598 & Poor & $33^{*}$ & 14 & 7 & 2.792 & $P<0.005$ \\
\hline
\end{tabular}

"Thirty one of the 33 negative ranks were calculated by cameras detecting one or more lion or leopard crossing events where the track observers did not detect any crossing, the remaining two were disagreement between methods in the count. 
Table 2 : Interobserver reliability and paired difference test for individual gaps and most commonly found species at those gaps (Jan 1 , 2011 to Dec 31, 2012)

\begin{tabular}{|c|c|c|c|c|c|c|c|c|c|c|}
\hline & \multicolumn{5}{|c|}{ Northern Gap } & \multicolumn{5}{|l|}{ Western Gap } \\
\hline & \multicolumn{3}{|c|}{ Interobserver reliability } & \multirow{2}{*}{\multicolumn{2}{|c|}{$\begin{array}{l}\text { Paired difference } \\
\text { test } \\
\text { Wilcoxon }\end{array}$}} & \multicolumn{3}{|c|}{ Interobserver reliability } & \multirow{2}{*}{\multicolumn{2}{|c|}{$\begin{array}{l}\text { Paired difference } \\
\text { test } \\
\text { Wilcoxon }\end{array}$}} \\
\hline & & & & & & & & Stmoth & & \\
\hline & $\mathrm{n}$ crossings & Kappa & agreement & Z & $P<$ & $\mathrm{n}$ crossings & Kappa & agreement & $\mathrm{Z}$ & $P<$ \\
\hline Elephant & 301 & 0.229 & Poor & 7.830 & 0.001 & 162 & 0.401 & Poor & 4.459 & 0.001 \\
\hline Hyaena & 224 & 0.357 & Poor & 8.042 & 0.001 & 126 & 0.355 & Poor & 7.218 & 0.001 \\
\hline Giraffe & 451 & 0.137 & Poor & 9.875 & 0.001 & 69 & 0.592 & Poor & 0.381 & 0.703 \\
\hline Common Zebra & 377 & 0.216 & Poor & 10.682 & 0.001 & 0 & n.a. & n.a. & n.a. & n.a. \\
\hline Grevy's Zebra & 359 & 0.3 & Poor & 4.933 & 0.001 & 0 & n.a. & n.a. & n.a. & n.a. \\
\hline Waterbuck & 1 & n.a. & n.a. & n.a. & n.a. & 71 & 0.119 & Poor & 6.909 & 0.001 \\
\hline Lion & 2 & n.a. & n.a. & n.a. & n.a. & 37 & 0.456 & Poor & 2.537 & 0.011 \\
\hline
\end{tabular}

detected or the direction of travel. The camera trap method detected more crossing events $(2,112$ versus 1,159$)$, more species (29 versus 11) as well as detecting twice the number of animals using the gaps (16,403 versus 7,857$)$ than were detected by the track observers. At this most general level, using pooled data from both the Northern fence gap (NG) and the Western fence gap (WG), we found agreement in 845 out of 2426 events (NG: 756/1865, WG: 87/561). Cameras detected 1267 (NG: 897, WG: 370) crossing events that were not detected by the track observers, conversely, the track observers detected 316 (NG: 212, WG: 104) crossing events that were not detected by the cameras. These raw results translated into negative kappa scores representing poor agreement between the two methods as detailed in the interobserver reliability section of Table 1. We found poor agreement between methods at all levels of inquiry.

The results of the paired differences tests are presented at the more general level in Table 1, and then presented by species in Table 2. Using the combined data from both gaps, the paired differences were significantly skewed towards the camera trap method with negative ranks (1685) outpacing positive ranks (560) by a ratio of 3:1 (Z $19.929, P<0.001$ ). Both fence gaps, taken sepa rately, also showed significant detection volume differences in favour of the camera traps. Significantly large detection differences in favour of the camera traps were also apparent irrespective of which direction the animals were travelling or for days that had above or below average traffic volume. Finally, significant detection differences in favour of the camera traps were also apparent at all of the individual species level, including when we pooled lion and leopard data, except for the case of the detection of giraffe (Giraffa camelopardalis) at the Western fence gap (Table 2).

\section{Discussion and management implications}

Camera trap monitoring reported a broader range of species and more individuals crossing the gaps than the human observers monitoring the same gaps by observing tracks left in a sandy strip of soil. The camera trap data are rich with information concerning time of travel, group size and predator prey interaction (prey potentially being followed) that could not be compared with the simple reporting scheme of the daily morning observation of tracks. We thus had to simplify the information from the camera traps in this study to make it directly comparable with the daily reporting schedule of the observers. We found that, contrary to our prediction, the agreement between detection methods was poor and the detection was heavily skewed towards the camera trap method. In similar analyses (camera traps versus track pads) used at crossing structures in North America, Ford, Clevenger \& Bennett (2009) reported some species detection differences between methods, as did Guzvica et al. (2014) in Croatia, although both reported general agreement between meth ods. Ford, Clevenger \& Bennett (2009) found that camera traps more readily detected some ungulate species and that some carnivore species were more often detected by track pads, whereas Guzvica et al. found the opposite. In our study, the detection differences were all heavily skewed towards the cameras, regardless of species. 
Tracking is dependent on two factors the skill of the observer and the suitability of the substrate (Liebenberg, 1990; Stander et al., 1997; Funston et al., 2010). The observers at our study site were highly trained, but their judgments were, by necessity, based on incomplete phys ical evidence. All human judgments are subject to some degree of error (Harris, 1915; Diefenbach, Brauning \& Mattice, 2003), even in skilled observers (Taylor, Skour ides \& Alvero, 2012; Stocks, van Hout \& Hautus, 2013). However, it is unlikely that the disagreement or detection differences were due entirely to human error. Both Ford, Clevenger \& Bennett (2009) and Guzvica et al. (2014) found that the composition and quality of the track pads affected detection rate. Guzvica et al. as well also found that a higher proportion of sand in the soil composition was detrimental to detection. The composition of the soil at our site was sandy loam, which may have been a contributing factor to the lower track detection rates. There was also a diel pattern in the usage of the Northern fence gap, where outbound traffic is heavier in the evening and inbound traffic is heavier in the morning (data from camera traps). This movement pattern might make it more difficult for the track observers to detect the outbound traffic as it may have been trampled over by inbound traffic.

We discovered that even at the very lowest traffic volumes the disagreement was still high. The fence gap locations were chosen along historic migration routes that crossed the fence line at a perpendicular angle. The wildlife using these routes have established permanent game trails at both gaps and tend to travel along it directly, as opposed to walking in flanked groups spread out across the landscape. Migrating animals, walking in file behind one another, thus naturally obliterate the tracks of those travelling ahead of them, even at low traffic volumes. It is likely that this phenomenon is also partly responsible for the lower detection rates of the track observers.

It is possible that certain animals approached the gaps at night but did not cross, thus not triggering the cameras but left spoor behind for the track readers to see the next morning. In addition, the fence gaps attract almost daily human traffic. The gaps permit access to the conservancy at points where there is no road access for several kilometres on either side. The camera traps have docu mented herders with their cattle, security personnel, curious tourists, community members as well as poachers using the gaps. One incident of poaching for bush meat was captured on camera when a member of the commu nity was photographed entering the conservancy and leaving a few hours later with bird in hand. However, we have had camera traps destroyed at another study site because the community suspected that these would be used to monitor hunters. Thus, we hesitate to promote the use of camera traps to prosecute poachers unless the cameras are safely housed and out of reach of people. Further, people often linger at the gaps and wander across the track pads, potentially obliterating tracks which fur ther reduces the probability of track detection.

We found it curious that the track observers detected 316 crossing events that were not detected by camera. Out of those 316 events, 71 involved predators, 14 of these were lions (9) or leopards (5), which are vitally important species to the human wildlife conflict reduction aims of the wildlife managers. Although the cameras potentially missed nine lion or leopard crossing events, the tracker observers definitely missed 31 crossing events. We inves tigated those 14 incidents in more detail and found that four of those incidents could be attributed to species misidentification where the cameras in these cases cap tured hyaena crossing, and we suspect that these tracks were misread by the track observers and reported as lion or leopard tracks (as the track observers had not reported any hyaena on those days). Regarding the other nine incidents, the cameras were functional and had detected the passage of other species during that day, however, did not detect these predators. This potential camera deficiency is some what worrying given the importance of monitoring these predators.

Motion activated sensors used in camera traps sometimes fail to detect the movement or heat differential required to trigger the camera, especially as the ambient temperature approaches the body temperature (Meek \& Pittet, 2012; Rovero et al., 2013; TrailcamPro, 2014). Further, different cameras, even cameras of the same make and model, can produce significantly different photographic data (Hughson, Darby \& Dungan, 2010). It is possible that some of the differences between the detection methods are attributable to the camera traps not firing properly. Our comparative test of Cameras 1 and 2 yielded only a fair agreement level. Even though the detection statistics between the cameras were adequate, of the 54 crossing events in the sample period, tweleve events were recorded by only one of the two cameras. Interestingly, 11 of these 12 crossing events involved leopard, spotted hyaena (Crocuta crocuta) or striped hyaena (Hyaena hyaena). We found that although the cameras were set for three rapid bursts, often only one clear 
photo of a predator would be taken, as predators would move mostly in the dead of night, and move quickly or low to the ground when passing over the exposed rock wall at the fence gaps. We found that the infrared flash units on the cameras were not always powerful enough to throw the infrared light in a wide enough beam to consistently give a clear picture, which has been reported before (Meek, 2012).

Although the cameras collected large amounts of data, there were issues associated with the camera maintenance and management of the data that are common to many other camera trap studies (Swann, Kawanishi \& Palmer, 2011; Barrueto et al., 2013). We lost a large number of study days due to cameras that were not functioning properly. Cameras were maintained every two weeks to collect SD memory cards and test batteries. During weeks of heavy traffic, the memory cards were quickly filled. In addition, because the bulk of crossing traffic was noctur nal, the infrared flash units were in constant use, draining the batteries quickly. We found that the management of the camera data was often given lower priority in daily management decisions than daily track reports, due to the immediate availability of the reports. This is a potential drawback to using camera traps for adaptive management goals since the time, effort and expense commitments can be unsuitable for supporting the timeframe in which critical decisions are made.

However, given the advantages of the richness of the camera trap data, it is important to find a way to use these data for more immediate managerial decision making. We thus recommend combining both methods by training the track observers to examine the camera data in the field on a daily basis and report the findings through their usual channels, effectively harnessing the best of each method.

\section{Acknowledgements}

The researchers would like to thank the conservation department team at the Lewa Wildlife Conservancy (in particular Geoffrey Chege), Marwell Wildlife, Mirka Ondrack, York University, Sina Ashour for data assistance, and the Kenya Wildlife Service for allowing this research to take place.

\section{References}

Ahumada, J.A., Silva, C.E.F., Gajapersad, K., Hallam, C., Hurtado, J., Martin, E., McWildiam, A., Mugerwa, B., O'Brien, T., Rovero, F., Sheil, D., Spironello, W.R., Winarni, N. \& Andelman, S.J.
(2011) Community structure and diversity of tropical forest mammals: Data from a global camera trap network. Philos. Trans. R. Soc. Lond. B Biol. Sci. 366, 27032711.

BALME, G.A., HunTER, L.T.B. \& SLOTOW, R. (2009) Evaluating methods for counting cryptic carnivores. J. Wildl. Manage. 73, 433441.

Barrueto, M., Clevenger, A.P., Dorsey, B. \& Ford, A.T. (2013) A better solution for photo classification, automatic storage and data input of camera data from wildlife crossing structures. Int. Conf. Ecol. Trans. (ICOET 2013), Scottsdale, Arizona, USA. Available at: http://www.icoet.net/ICOET 2013/cocuments/ papers/ICOET 2013 Paper402B Baruetto et al.pdf (Accessed on 3 Jan 2016).

Burton, A.C. (2012) Critical evaluation of a long term, locally based wildlife monitoring program in West Africa. Biodivers. Conserv. 21, 30793094.

Clevenger, A.P. (2005) Conservation value of wildlife crossings: Measures of performance and research directions. GAIA 14, 124129 .

Diefenbach, D.R., Brauning, D.W. \& Mattice, J.A. (2003) Variability in grassland bird counts related to observer differences and species detection rates. Auk 120, 11681179.

Elbroch, M., Mwampamba, T.H., Santos, M.J., Zylberberg, M., Liebenberg, L., Minye, J., Mosser, C. \& Reddy, E. (2011) The Value, limitations, and challenges of employing local experts in conservation research. Conserv. Biol. 25, 11951202.

Ford, A.T., Clevenger, A.P. \& Bennett, A. (2009) Comparison of methods of monitoring wildlife crossing structures on highways. J. Wildl. Manage. 73, 12131222.

Funston, P.J., Frank, L., Stephens, T., Davidson, Z., Loveridge, A., Macdonald, D.M., Durant, S., Packer, C., Mosser, A. \& Ferreira, S.M. (2010) Substrate and species constraints on the use of track incidences to estimate African large carnivore abundance. J. Zool. (Lond.) 281, 5665.

Gagnon, J.W., Dodd, N.L., Ogren, K.S. \& Schweinsburg, R.E. (2011) Factors associated with use of wildlife underpasses and importance of long term monitoring. J. Wildl. Manage. 75, 14771487.

GibBs, J.P., Snell, H.L. \& Causton, C.E. (1999) Invited Paper: Effective monitoring for adaptive wildlife management: Lessons from the Galapagos Islands. J. Wildl. Manage. 63, 10551065.

Gusset, M. \& Burgener, N. (2005) Estimating larger carnivore numbers from track counts and measurements. Afr. J. Ecol. 43, 320324.

Guzvica, G., Bosnjak, I., Bielen, A., Babic, D., Radanovic Guzvica, B. \& SVER, L. (2014) Comparative Analysis of Three Different Methods for Monitoring the Use of Green Bridges by Wildlife. PLoS ONE 9, e106194.

HARRIS, J.A. (1915) Experimental data on errors of judgment in the estimation of the number of objects in moderately large samples, with special reference to personal equation. Psychol. Rev. 22, 490511.

Hughson, D.L., Darby, N.W. \& Dungan, J.D. (2010) Comparison of motion activated cameras for wildlife investigations. Calif. Fish Game 96, 101109. 
LANDIS, J.R. \& KосH, G.G. (1977) Measurement of observer agreement for categorical data. Biometrics 33, 159174.

Liebenberg, L. (1990). The Art of Tracking. David Philip Publishers (Pty) Ltd, Cape Town.

Lyons, J.E., Runge, M.C., Laskowski, H.P. \& Kendall, W.L. (2008) Monitoring in the Context of Structured Decision Making and Adaptive Management. J. Wildl. Manage. 72, 16831692.

MeEк, P. (2012) Refining and Improving the Use of Camera Trap Technology for Wildlife Management and Research in Australia and New Zealand. The Winston Churchill Memorial Trust of Australia, Canberra.

MEек, P.D. \& PітTET, A. (2012) User based design specifications for the ultimate camera trap for wildlife research. Wildl. Res. 39, 649660.

Rovero, F. \& Marshall, A.R. (2009) Camera trapping photographic rate as an index of density in forest ungulates. J. Appl. Ecol. 46, 10111017.

Rovero, F., Zimmermann, F., BerZi, D. \& Meek, P. (2013) "Which camera trap type and how many do I need?" A review of camera features and study designs for a range of wildlife research applications. Hystrix-Italian J. Mammal. 24, 148156.

STANDER, P.E. (1998) Spoor counts as indices of large carnivore populations: the relationship between spoor frequency, sampling effort and true density. J. Appl. Ecol. 35, 378385. Stander, P.E., Ghau, II., Tsisaba, D., Oma, II. \& VI, L.L. (1997) Tracking and the interpretation of spoor: a scientifically sound method in ecology. J. Zool, 242, 329341.
Stocks, M.A., van Hout, D. \& Hautus, M.J. (2013) Cognitive decision strategies adopted in reminder tasks by trained judges when discriminating aqueous solutions differing in the concentration of citric acid. J. Sens. Stud. 28, 217229.

Swann, D.E., KaWAnishi, K. \& Palmer, J.S. (2011) Evaluating types and features of camera traps in ecological studies: a guide for researchers. In: Camera Traps in Animal Ecology (Eds. A. F. O'Conneli, J. D. Nichols and K. U. Karanth). Springer, Tokyo, Japan, ISBN 9784431994954.

Taylor, M.A., Skourides, A. \& Alvero, A.M. (2012) Observer error when measuring safety related behavior: momentary time sampling versus whole interval recording. J. Organ. Behav. Manage. 32, 307319.

Trailcampro (2014) Spring Trail Camera Shootout [Online]. Available: http://www.trailcampro.com/trailcamerashootout. aspx (Accessed 22 February 2015).

WhITE, F. (1983) Vegetation of Africa a descriptive memoir to accompany the Unesco/AETFAT/UNSO vegetation map of Africa. Natural Resources Research Report XX. U.N. Educational, Scientific and Cultural Organization, Paris, France. Wolf, K.N., Elvinger, F. \& Pilcicki, J.L. (2003) Infrared triggered photography and tracking plates to monitor oral rabies vaccine bait contact by raccoons in culverts. Wildl. Soc. Bull. 31, 387 391.

(Manuscript accepted 11 December 2015)

doi: $10.1111 /$ aje.12277 